\title{
Kendali Kecepatan Motor DC Menggunakan Chopper DC Dua Kuadran Berbasis Kontroller PI
}

\author{
Febri Rahmadi ${ }^{1}$, Muldi Yuhendri ${ }^{2}$ \\ 1'2Jurusan Teknik Elektro, Faklutas Teknik, Universitas Negeri Padang \\ Jl. Prof. Dr. Hamka, Air Tawar Padang, Sumatera Barat, 25132, Indonesia. \\ Febrirahmadi01@gmail.com ${ }^{1}$, muldiy@ft.unp.ac.id ${ }^{2}$
}

\begin{abstract}
DC (Direct Current) motor is one of drive which is widely used in industry. DC motor as a drive has several advantages compared with AC (Alternating Current) motor. One of the advantages use DC motor as drive in industry because has a starting big torque and rotation speed motor can be set up easily in the range wide variation of rotation. One of speed setting DC motor can use DC Chopper two quadrant. Speed control DC motor with DC Chopper two quadrant is a method for speed control motor DC can operate for two condition which can be stated in the quadrant system. For one quadrant DC motor can operate for forward motoring and the second quadrant DC motor can operate for renegerative breaking. DC Chopper is a electronic circuits can change value voltage and current $D C$ source, and can using for speed control and operate DC motor. For system control used controller PI (proportional integral) for feedback parameter mechanics and electrick DC motor. For controller PI can work for system control used Simulink software for programming, and also works for interfece to displays real times condition parameters work operate DC motor.
\end{abstract}

Keywords - DC motor, two quadran DC Chopper, PWM, PI controller, matlab.

\begin{abstract}
Abstrak- Motor DC (Direct Current) merupakan salah satu jenis penggerak yang banyak digunakan untuk berbagai keperluan, karena memiliki beberapa keunggulan antara lain torsi awal yang besar dan kecepatan putaran mudah diatur dalam rentang variasi yang lebar. Salah satu cara mengendalikan kecepatan motor DC adalah dengan mengatur tegangan jangkar menggunakan konverter daya. Penelitian ini mengusulkan kendali kecepatan motor DC menggunakan chopper DC dua kuadran berbasis kontroller Proportional Integral (PI). Chopper DC dua kuadran ini dapat digunakan untuk operasi mesin DC pada kondisi forward motoring dan reverse regenerating. Kontroller PI dirancang untuk dua loop kontrol, yaitu loop kontrol kecepatan untuk mendapatkan arus referensi dan loop kontrol arus untuk mendapatkan duty cycle pulsa PWM. Kendali kecepatan motor DC yang diusulkan ini diimplementasikan dengan arduino mega yang diprogram menggunakan simulink Matlab. Sistem kendali kecepatan motor DC yang dirancang dalam penelitian ini diuji melalui eksperimen pada motor DC penguat terpisah. Hasil eksperimen menunjukan bahwa kendali kecepatan motor yang diusulkan menggunakan chopper DC dua kuadran berbasis kontroller PI telah sukses mengendalikan kecepatan motor sesuai dengan nilai referensi yang diinginkan.
\end{abstract}

Kata kunci- Motor DC, Chopper DC dua kuadran, PWM, kontroller PI, matlab.

\section{Pendahuluan}

Motor DC merupakan salah satu jenis motor listrik yang banyak digunakan sebagai penggerak berbagai mesin di industri. Hal ini disebabkan oleh kekelebihan yang dimilikinya, seperti kebih mudah mengatur kecepatan dengan rentang variasi yang besar, torsi awal yang besar dan sebagainya [1]-[3]. Pengaturan kecepatan motor DC dapat dilakukan dengan tiga cara, yaitu pengaturan dengan tahanan sisipan pada rangkaian kumparan jangkar motor, pengaturan tegangan jangkar motor, dan pengaturan arus medan [4]-[5]. Pengaturan kecepatan putaran motor DC dengan pengaturan tegangan jangkar merupakan salah satu cara yang paling efektif digunakan untuk variasi putaran motor yang lebar. Kendali kecepatan motor DC dengan pengaturan tegangan jangkar memerlukan suatu regulator tegangan yang dapat bekerja dengan kecepatan tinggi dan memiliki perubahan variabel tegangan yang lebar.
Salah satu jenis regulator tegangan DC yang dapat digunakan untuk kendali kecepatan motor DC adalah chopper DC, yaitu rangkaian konverter daya yang dapat merubah suatu besaran nilai input tegangan DC menjadi lebih besar ataupun lebih kecil sesuai dengan tipenya [6][7]. Pengendalian kecepatan putaran motor DC dengan chopper DC dinyatakan dalam sistem kuadran. Ada beberapa jenis chopper DC, yaitu chopper DC satu kuadran, dua kuadran dan empat kuadran [6]. Penelitian ini mengusulkan chopper DC dua kuadran untuk kendali kecepatan motor DC. Chopper DC dua kuadran ini dapat dioperasikan pada kuadran forward motoring dan reverse regenerating.

Pengaturan kecepatan motor dc dengan Chopper DC dua kuadran dilakukan dengan mengatur tegangan keluaran Chopper DC melalui pengaturan arus jangkar. Pengaturan arus jangkar ini membutuhkan kontroller dalam bentuk loop tertutup. Secara umum, kendali kecepatan motor dc menggunakan Chopper DC menggunakan dua loop 
kontroller, yakni loop kontrol kecepatan dan loop kontrol arus. Loop kontrol kecepatan berfungsi mendapatkan arus referensi berdasarkan error kecepatan, sedangkang loop kontrol arus berfungsi untuk mencari nilai duty cycle PWM sakelar Chopper DC berdasarkan error arus jangkar. Beberapa metode kontrol telah diterapkan untuk kedua loop kontrol pada kendali kecepatan motor DC, seperti metode kontroller PI dan PID [8]-[13], logika fuzzy [14] serta gabungan fuzzy dengan PID [15]. Penelitian ini mengusulkan kontroller PI untuk meregulasi arus dan kecepatan. Metode ini dipilih karena mudah diimplementasikan. Sistem kendali kecepatan motor DC dengan Chopper DC dua kuadran yang diusulkan ini diimplementasikan menggunakan Arduino Mega 2560 sebagai pusat kendali yang diprogram melalui simulink Matlab. Alat yang dibuat juga dilengkapi dengan keypad sebagai input data kecepatan referensi dan LCD untuk menampilkan data kecepatan. Alat yang dibuatkan ini diujicobakan pada motor DC penguat terpisah 2.2 HP.

\section{Metode}

Penelitian tentang sistem kendali kecepatan motor DC menggunakan Chopper DC dua kuadran berbasis kontroller PI ini dilakukan dalam bentuk eksperimen di laboratorium. Motor DC yang akan dikendalikan adalah motor DC jenis penguatan terpisah. Motor DC penguatan terpisah merupakan salah satu jenis dari motor DC yang memerlukan dua sumber tegangan yang terpisah untuk mengoperasikannya, yang terdiri dari sumber tegangan untuk kumparan jangkar dan tegangan untuk kumparan medan. Gambar 1 menunjukan skema motor DC penguat terpisah yang akan diuji dalam penelitian ini.

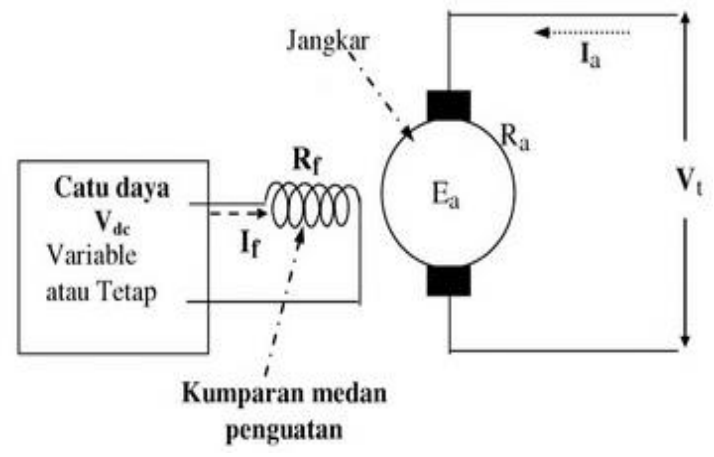

Gambar 1. Skema motor DC penguat terpisah

Pengaturan kecepatan motor DC dilakukan dengan mengatur tegangan jangkar $V_{a}$, sesuai dengan Persamaan kecepatan yang diirumuskan dalam Persamaan 1 berikut :

$$
\omega_{m}=\frac{V_{t}-I_{a} R_{a}}{T_{a}}
$$

Dimana $I_{a}, R_{a}$ dan $T_{a}$ adalah arus jangkar, tahanan jangkar dan torsi elektromagnetik. Gambar 1 menunjukan bahwa kecepatan motor DC dapat diatur dengan mengendalikan tegangan jangkar, dimana pengaturan tegangan jangkar ini dapat dilakukan dengan menggunakan konverter daya. Jenis konverter daya yang diusulkan untuk mengendalikan tegangan jangkar ini adalah Chopper DC dua kuadran. Gambar 2 menunjukan skema Chopper DC dua kuadran yang digunakan untuk kendali kecepatan motor DC.

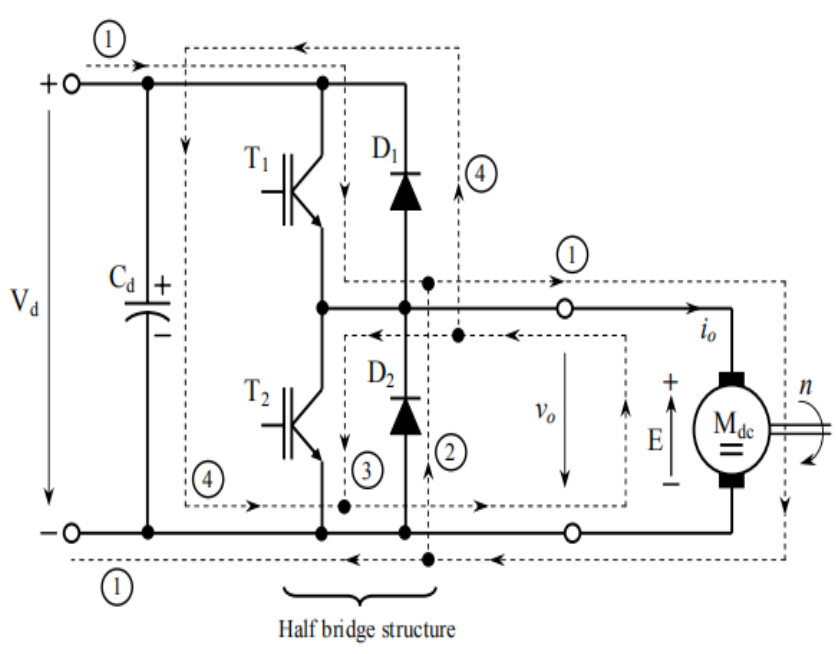

Gambar 2. Skema motor DC penguat terpisah

Gambar 2 menunjukan bahwa Chopper DC dua kuadran terdiri dari dua buah semikonduktor daya aktif yang disusun dalam bentuk struktur setengah jembatan. Pengaturan tegangan keluaran Chopper DC dua kuadran untuk mengendalikan kecepatan motor DC dilakukan dengan mengatur waktu konduksi kedua sakelar daya tersebut. Salah satu cara mengatur waktu konduksi sakelar daya adalah dengan menggunakan metode Pulse Width Modulation (PWM). Waktu konduksi sakelar dengan metode PWM ditentukan oleh nilai duty cycle. Nilai duty cycle ini diperoleh dengan cara mengatur arus jangkar menggunakan metode kontroller PI. Gambar 3 menunjukan skema sistem kendali kecepatan motor DC menggunakan kontroller PI berbasis Chopper DC dua kuadran.

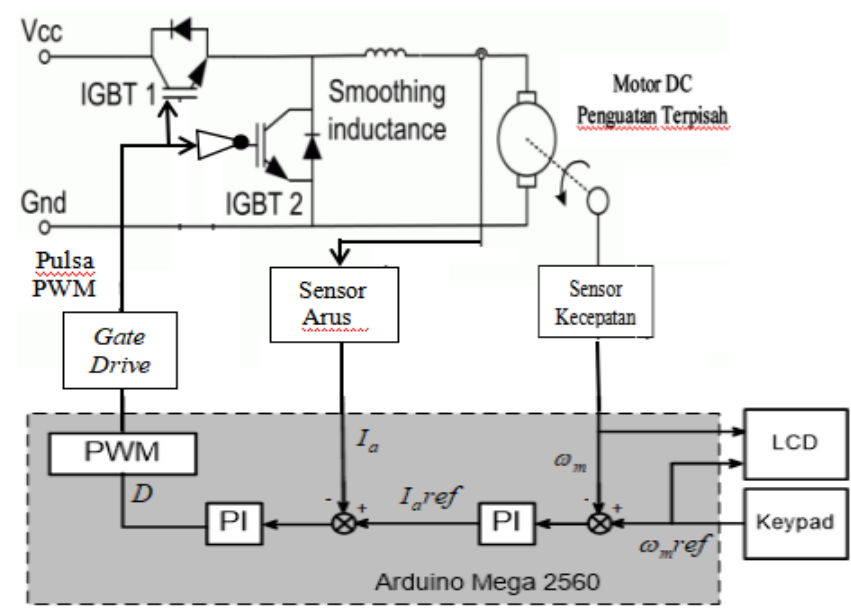


Gambar 3. Skema sistem kendali motor DC

Gambar 3 menunjukan bahwa sistem kendali kecepatan motor DC yang dirancang menggunakan dua loop kontrol, yaitu loop kontrol arus dan loop kontrol kecepatan. Kedua loop kontrol didesain menggunakan metode PI. Loop kontrol kecepatan berfungsi untuk mencari arus jangkar referensi berdasarkan error kecepatan, dimana error kecepatan tersebut diperoleh dari perbandingan antara kecepatan referensi yang diinputkan melalui keypad dengan kecepatan terukur yang diperoleh dari sensor kecepatan motor. Loop kontrol arus berfungsi untuk mencari nilai duty cycle PWM untuk modulasi sakelar Chopper DC dua kuadran berdasarakan error arus jangkar. Error arus jangkar diperoleh dari perbandingan antara arus jangkar referensi yang didapat dari output kontrol kecepatan dengan arus terukur yang didapat dari sensor arus. Kedua loop kontrol PI ini dirancang menggunakan arduino Mega 2560 yang diprogram dengan menggunakan simulink Matlab. Gambar 4 menunjukan skema rangkaian arduino Mega untuk kendali kecepatan motor yang diusulkan dalam penelitian ini.

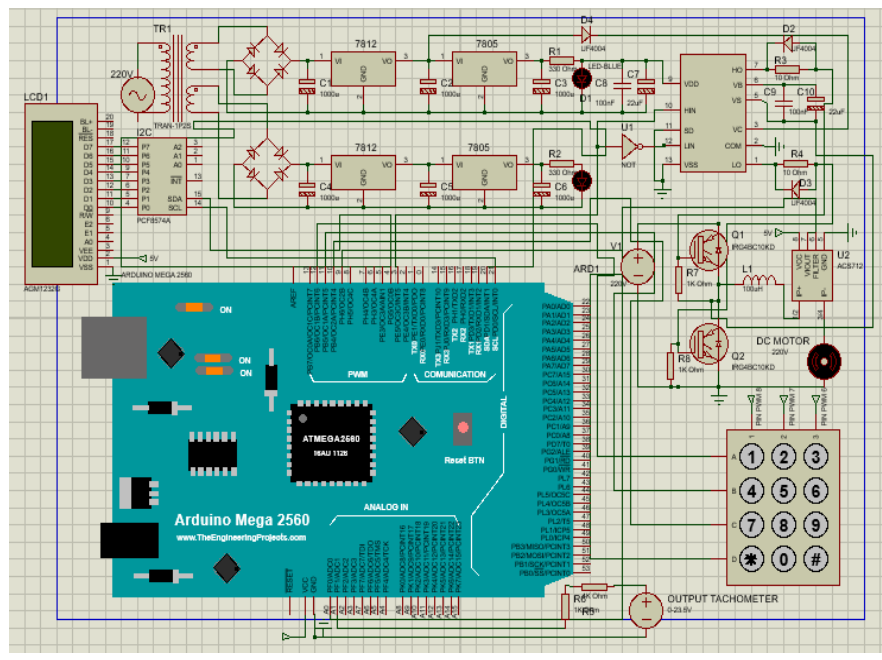

Gambar 4. Skema rangkaian sistem kendali kecepatan motor DC

Gambar 4 menunjukan bahwa ada tiga bagian yang menjadi input arduino, yaitu sensor arus dan sensor kecepatan yang dihubungkan dengan pin analog input arduino serta keypad yang dihubungkan dengan pin digital input arduino. Sedangkan output arduino yaitu pulsa PWM untuk sakelar daya Chopper DC dua kuadran yang dihubungkan dengan gate driver melalui pin output PWM arduino dan LCD yang dihubungkan dengan pin digital output arduino. Sakelar daya yang digunakan untuk Chopper DC dua kuadran adalah IGBT sedangkan gate driver nya adalah IR 2110. Rangkaian ini juga dilengkapi dengan catu daya 5 Volt dan 12 Volt untuk suplai tegangan arduino dan rangkaian gate driver IGBT. Gambar 5 menunjukan hasil pembuatan rangkaian sistem kendali kecepatan motor DC menggunakan Chopper DC dua kuadran.

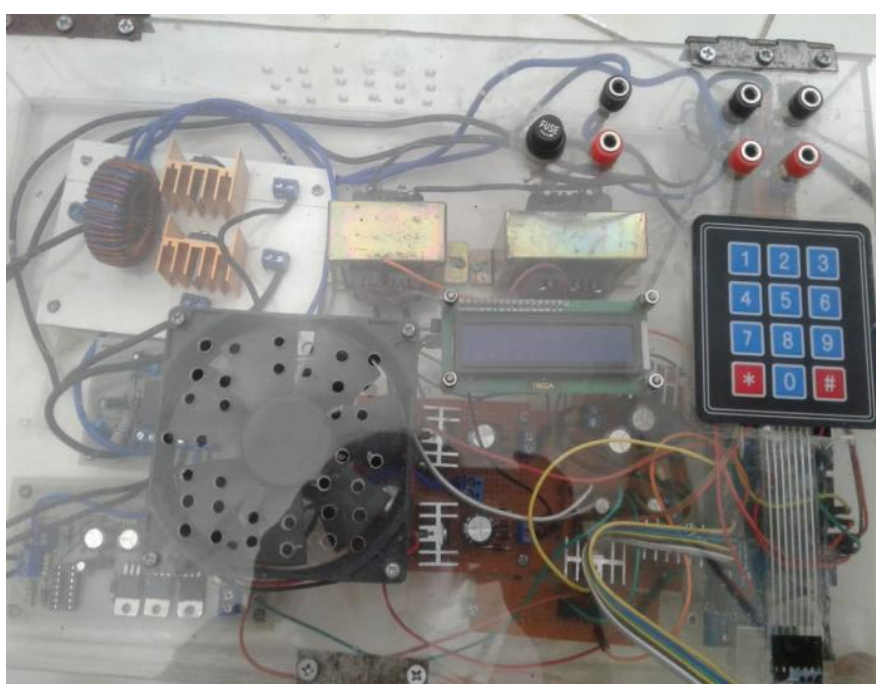

Gambar 5. Hardware sistem kendali kecepatan motor DC

Pembuatan program sistem kendali kecepatan motor DC berbasis kontroller PI ini dilakukan dengan menggunakan software simulink Matlab. Gambar 6 menunjukan bentuk program kendali kecepatan motor DC menggunakan Chopper DC dua kuadran yang dibuat dalam simulink Matlab.

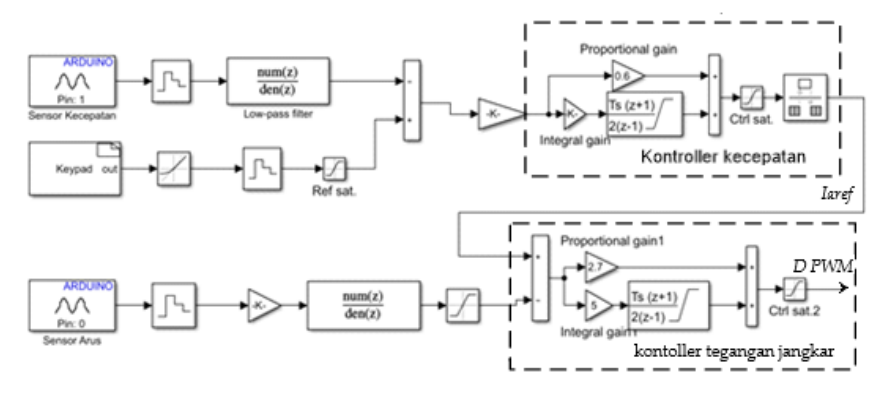

Gambar 6. Program sistem kendali kecepatan motor DC dalam simulink Matlab

\section{HASIL DAN PEMBahaSAN}

Alat sistem kendali kecepatan motor DC yang telah selesai dibuat diujikan pada motor DC penguat terpisah $2.2 \mathrm{HP}$. Motor diuji dengan kecepatan yang bervariasi pada kondisi tanpa beban dan kondisi berbeban. Motor yang diuji ini dihubungkan dengan mesin DC yang berfungsi sebagai beban nanti, dimana mesin DC ini dioperasikan sebagai generator dengan beban resistor pada saat pengujian motor DC berbeban. Untuk mengetahu kecepatan putaran motor, digunakan tachogenerator yang dihubungkan dengan input analoh arduino. Gambar 7 menunjukan skema dan instalasi pengujian sistem kendali kecepatan motor DC yang diusulkan dalam penelitian ini. 


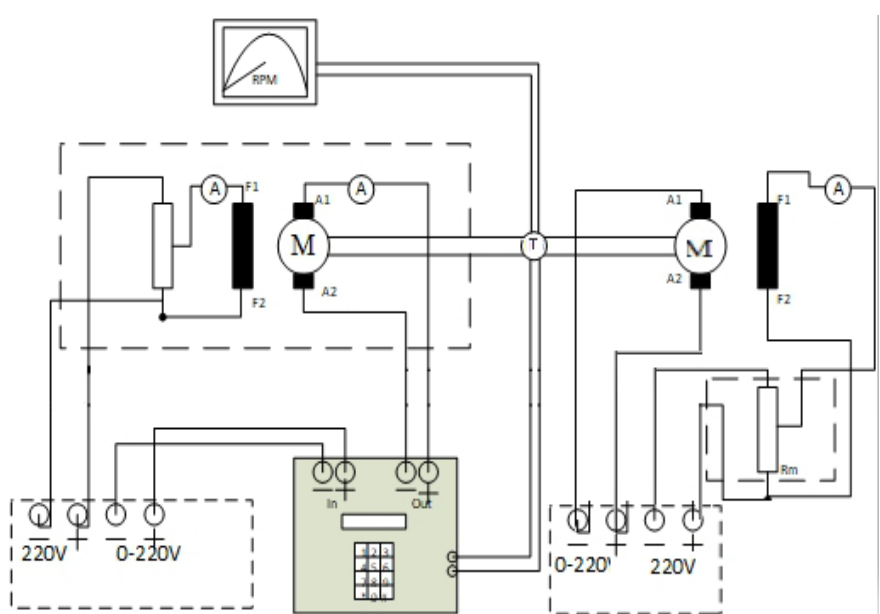

(a)

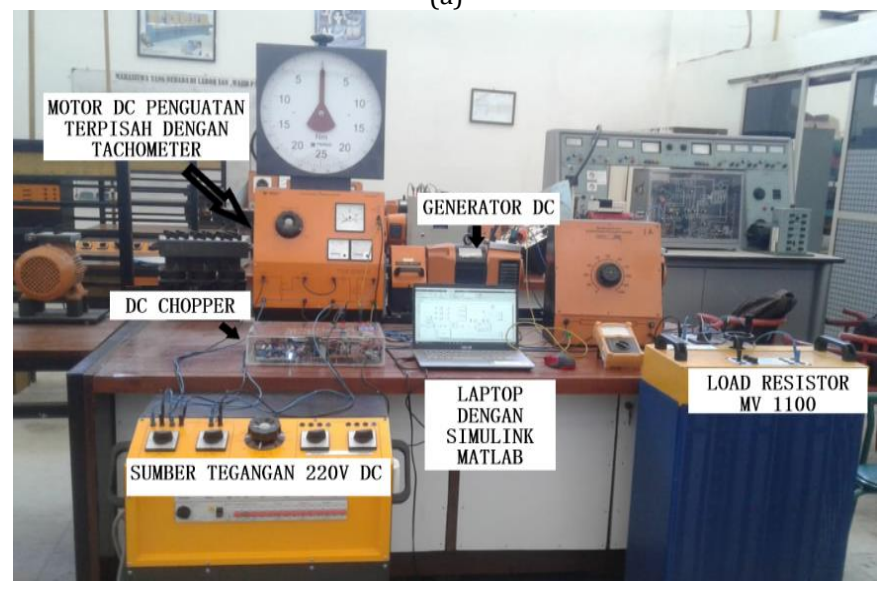

(b)

Gambar 7. Skema dan instalasi pengujian sistem kendali kecepatan motor DC . (a)Skema rangkaian dan (b) instalasi rangkaian pengujian

Eksperimen pertama dilakukan pengujian sistem kendali kecepatan motor DC pada kuadran 1 tanpa beban. Dalam pengujian ini, kecepatan referensi motor diset sebesar 500 rpm melalui keypad. Gambar 8 menunjukan respon kecepatan motor pada saat motor dioperasikan tanpa beban.

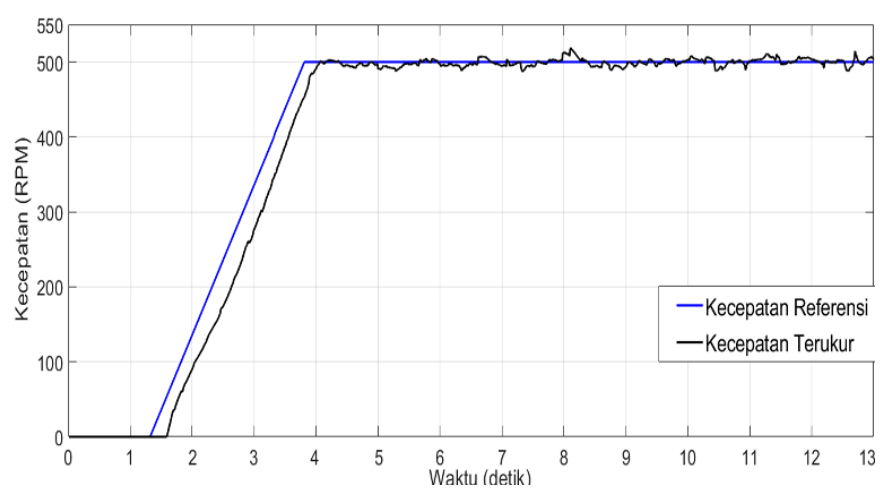

Gambar 8. Respon kecepatan motor DC pada pengujian tanpa beban.
Gambar 8 menunjukan bahwa kecepatan terukur motor telah mampu mengikuti kecepatan referensi motor yang diinputkan melalui keypad. Hal ini menunjukan bahwa desain sistem kendali kecepatan motor yang dirancang menggunakan chopper DC dua kuadran berbasis kontroller PI telah bekerja dengan baik. Kinerja sistem kendali yang cukup bagus ini tidak terlepas dari kevalidan kontroller PI dalam mengendalikan arus jangkar motor. Gambar 9 menunjukan respon arus jangkar motor dalam pengujian ini.

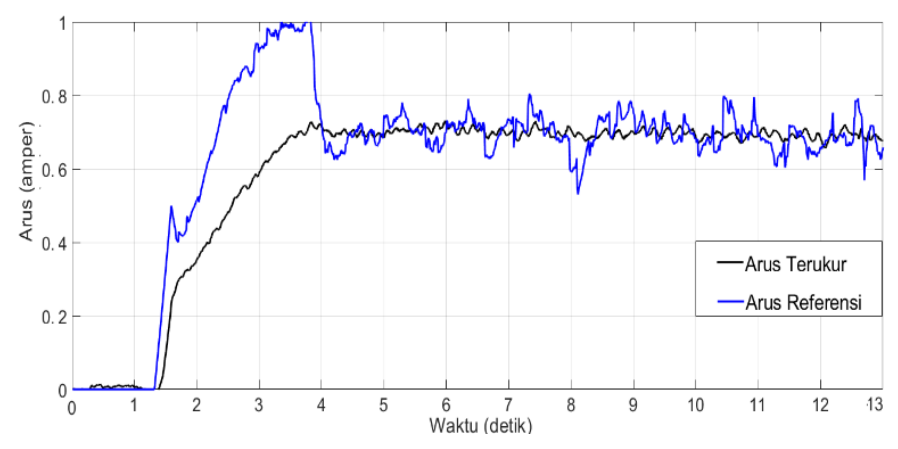

Gambar 9. Respon arus jangkar motor DC pada pengujian tanpa beban.

Gambar 9 menunjukan bahwa arus jangkar motor terukur sudah mampu mengikuti arus jangkar referensi pada kondisi tunak. Error terbesar arus jangkar hanya terjadi pada kondisi transien, yaknik pada kondisi motor mulai operasi. Pada kondisi awal motor beroperasi terjadi lonjakan arus jangkar akibat starting motor, tapi pada kondisi tunak arus jangkar ini bisa mengikuti arus jangkar referensi yang diperoleh dari output kontroller PI pada blok kontrol kecepatan. Hasil ini menunjukan bahwa kedua loop kontrol, baik loop kontrol arus maupun loop kontrol kecepatan yang dirancang menggunakan kontroler PI untuk mengendalikan kecepatan motor DC telah bekerja dengan baik.

Tahap selanjutnya dilakukan dilakukan pengujian sistem kendali kecepatan motor DC berbeban. Dalam pengujian ini, mesin DC yang menjadi beban motor DC dihubungkan dengan beban resistor. Hal ini mengindikasikan bahwa mesin DC kedua bekerja sebagai generator. Dalam pengujian kedua ini, kecepatan referensi motor DC diset sebesar 500 rpm melalui keypad. Saat awal operasi, motor beroperasi tanpa beban, kemudian setelah kecepatan motor mencapai kondisi tunak, maka beban mesin DC kedua dihubungkan ke beban resistor.

Gambar 10 menunjukan bahwa motor DC tetap dapat mempertahankan kecepatannya ketika motor diberi beban. Pada saat awal motor dihubungkan ke beban pada waktu 8 detik, kecepatan motor mengalami penurunan pada masa transien. Dalam beberapa saat kecepatan motor kembali mencapai kecepatan referensinya pada kondisi tunak. Hal ini menunjukan bahwa desain kontroller PI yang dibuat untuk mengendalikan kecepatan motor DC telah bekerja dengan baik dalam mengendalikan kecepatan motor walaupun beban divariasikan. 


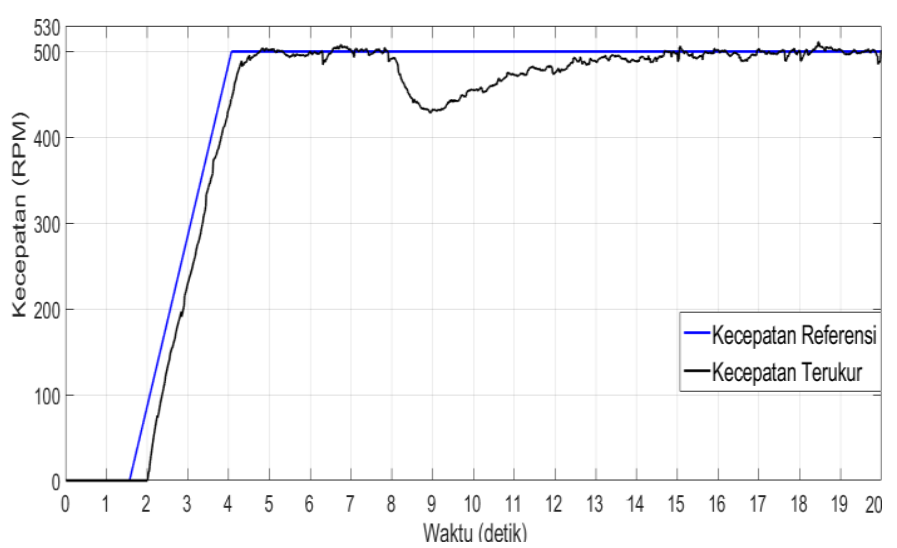

Gambar 10. Respon kecepatan motor DC pada pengujian berbeban.

Akurasi respon kecepatan motor yang ditunjukan oleh Gambar 10 tidak terlepas dari keakuratan kontroller PI dalam mengendalikan arus jangkar motor. Gambar 11 menunjukan respon arus jangkar motor pada saat operasi berbeban.



Gambar 11. Respon arus motor pada pengujian berbeban.

\section{PENUTUP}

Penelitian ini mengusulkan sistem kendali kecepatan motor DC menggunakan chopper DC dua kuadran berbasis kontroller PI. Rancangan sistem yang diusulkan diimplementasikan dengan menggunakan arduino Mega 2560 yang diprogram menggunakan simulink Matlab. Hasil pengujian menunjukan bahwa sistem kendali motor DC yang diusulkan menggunakan chopper DC dua kuadran telah bekerja dengan baik, dimana kecepatan motor dapat mengikuti kecepatan referensi baik pada kondisi tanpa beban maupun pada kondisi berbeban.

\section{REFERENSI}

[1] D. Singh, S. Kumar, and S. S. Thakur, "A Technique to Simulate Two Quadrant DC Chopper Fed Drives," International Journal of Engineering Research \& Technology (IJERT), vol. 3, no. 2, pp. 19091912, 2014.

[2] M. Yuhendri, Ahyanuardi dan Aswardi, "Direct Torque Control Strategy of PMSM Employing Ultra Sparse Matrix Converter," International Journal of Power Electronics and Drive Systems, vol. 9, no. 1, pp. 64-72, 2018

[3] A. Budijanto, "Pengaturan kecepatan motor DC pada robot line follower menggunakan pulse width modulation (pwm)," Senasif, pp. 20-26, 2018

[4] C. Ibrahim, T. Sukmadi, and A. Nugroho, "Perancangan Pengontrolan Motor DC Menggunakan DC - DC Konverter Class C Mode Motoring Dan Regenerative Breaking Untuk Simulasi Kendaraan Listrik," Transient, vol. 5, no. 3, pp. 339-344, 2016.

[5] R. Singhal, S. Padhee, and G. Kaur, "Design of Fractional Order PID Controller for Speed Control of DC Motor," International Journal of Scientific and Research Publications, vol. 2, no. 6, pp. 1-8, 2012.

[6] M. D. O. Rahul Baranwal , Omama Aftab, "Four Quadrant Speed Control of DC Motor with the Help of AT89S52 Microcontroller," International Journal of Advance Research in Science and Engineering, vol. 01, no. 08, pp. 9-17, 2015

[7] Aswardi, M. Yuhendri dan D. T. Yanto, Teknik Elektronika Daya, Indonesia : IRDH Book Publisher, 2020.

[8] R. Nagarajan, S. Sathishkumar, K. Balasubramani, C. Boobalan, S Naveen, and N. Sridhar, "Chopper Fed Speed Control of DC Motor Using PI Controller," IOSR Journal of Electrical and Electronics Engineering, vol. 11, no. 3, pp. 65-69, 2016

[9] M. I. Esario and M. Yuhendri, "Kendali Kecepatan Motor DC Menggunakan DC Chopper Satu Kuadran Berbasis Kontroller PI,' Jurnal Teknik Elektro dan Vokasional (JTEV), vol. 06, no. 01, pp. 296-305, 2020.

[10] W. M. Elsrogy, M. A. Fkirin, and M. A. M. Hassan, "Speed control of DC motor using PID controller based on artificial intelligence techniques," 2013 International Conference on Control, Decision and Information Technologies, vol. 4, no. 6, pp. 196-201, 2013

[11] F. Suryatini and A. Firasanti, "Kendali P , PI , Dan PID Analog Pada Pengaturan Kecepatan Motor DC Dengan Penalaan Ziegler-Nichols," Journal of Electrical and Electronics, vol. 6, no.1, pp. 65-80, 2018

[12] Rosalina, I. Qosim, and M. Mujirudin, "Analisis Pengaturan Kecepatan Motor DC Menggunakan Kontrol PID ( Proportional Integral Derivative )," Prosiding Seminar Nasional TEKNOKA, vol. 2, pp. 89-94, 2017

[13] M. Fauziyah, D. Dewatama, and M. Atisobhita, "Implementas Kontrol PI Pada Pengaturan Kecepatan Motor DC," Prosiding Seminar Nasional Teknologi Elektro Terapan, vol. 01, no. 01, pp. 217-222, 2017

[14] J. N. Rai, "Speed Control of DC Motor Using Fuzzy Logic Technique," IOSR Journal of Electrical and Electronics Engineering, vol. 3, no. 6, pp. 41-48, 2012

[15] M. Asbi, S. Subiyanto, and Y. Primadiyono, "Simulasi Kendali Motor DC Penguat Terpisah Menggunakan Kendali Fuzzy-FOPID," Jurna Ilmiah Teknik Elektro, vol. 17, no. 1, p. 99, 2019.

\section{Biodata Penulis}

Febri Rahmadi Menyelesaikan studi DIV Teknik Elektro Industri pada Jurusan Teknik Elektro Fakultas Teknik Universitas Negeri Padang..

Muldi Yuhendri, lahir di Kampung Aur, 13 Desember 1981. Sarjana Pendidikan Teknik Elektro, Universitas Negeri Padang tahun 2005 S2 Teknik Elektro Sistem Tenaga, ITS tahun 2009, S3 Ilmu Teknik Elektro, ITS tahun 2017. Staf pengajar pada jurusan teknik elektro FT UNP sejak tahun 2006 sampai sekarang. 